\title{
Escola cidadã no Paraná: análise de seus avanços e retrocessos
}

\author{
Rosilda Baron Martins*
}

\begin{abstract}
RESUMO
Este estudo trata da análise da política educacional paranaense desenvolvida no período 1991-1994, com destaque para o Projeto Construindo a Escola Cidadã. A intenção foi apreender o processo de formulação, implantação de política pública e a visão dos diferentes atores envolvidos nas etapas de sua concretização. Pretendeu-se contribuir para a compreensão e análise da educação e verificar a que contextos as políticas educacionais estão articuladas, quais os avanços concretos na prática a partir das intenções expressas nos discursos, e como as orientações formuladas foram introjetadas ou rejeitadas no imaginário dos atores envolvidos. Buscou-se a análise dos planos de governo do Partido do Movimento Democrático Brasileiro - PMDB no Paraná, salientando os aspectos fundamentais, as características e a coerência das propostas.
\end{abstract}

Palavras-chave: política educacional, políticas públicas, cidadania, autonomia, gestão educacional

A política educacional paranaense começou a sofrer alterações mais significativas a partir de 1983, quando assumem o poder os candidatos eleitos por eleições diretas. No decorrer de 12 anos, o Estado do Paraná foi governado pelo Partido do Movimento Democrático - PMDB.
A primeira reforma marcante deuse no ano de 1982 com a mudança no cenário político-econômico-social brasileiro. A década de 80 que se inicia com o discurso da abertura política, traz o discurso da democratização na educação em todos os níveis. Implícita nesta proposta, que

\footnotetext{
*Professora do Departamento de Métodos e Técnicas de Ensino da Universidade Estadual de Ponta Grossa - Doutora em Educação.

Olhar de professor, Ponta Grossa, 1(1):129-148, out. 1998.
} 
era de acesso e permanência da população na escola pública, vinha a recuperação da função específica da escola, como mediadora entre o conteúdo socialmente produzido e o aluno, como concepção de escola pública de qualidade.

No Paraná, para a consecução de tais propostas, a Gestão Richa (19831986), estabeleceu metas que visavam a melhoria da qualidade do ensino pela valorização dos profissionais da educação e de seu aperfeiçoamento no resgate de sua competência.

No que se refere à democratização da educação, além das práticas com vistas ao acesso e à permanência do aluno, foram deflagradas medidas democratizantes como descentralização de decisões, eleição direta de diretores, além da proclamação de uma postura mais aberta e democrática na própria administração na sua relação com a escola.

Estas metas mais presentes no período de 1983 a 1986, passam a ser adotadas também nas gestões seguintes, com encaminhamentos diversos. No Governo Álvaro Dias (87-90), aparecem com as propostas de competência, de eficiência e de produtividade, inseridas nas políticas educacionais. Essa linha ideológica tornou-se mais visível no Governo Requião (91-94), com medidas de autonomia consentida das escolas, a imposição dos Conselhos Escolares, a municipalização realizada coercitivamente, acompanhadas de uma política centralista e autoritária.
As reflexões realizadas a respeito das políticas educacionais implantadas pelos governos do PMDB, revelam que os discursos das autoridades educacionais estão repletos de belas propostas que nunca chegam a se concretizar. Inicialmente porque, no momento de sua execução, ora falta vontade política, ora faltam os recursos para levá-los efetivamente a bom termo. Para completar esse quadro desanimados, quando propostas de mudanças consistentes surgem, às vezes, por iniciativa do governo e, outras vezes, por ação de entidades representativas, os homens que fazem a educação passam, o seu tempo esgota e, com eles, o ápice das idéias amadurecidas. Parece que as diferentes propostas não conseguem escapar do círculo vicioso que gera outros comportamentos diante de tudo o que se fez e perante tudo o que essencialmente deve permanecer.

Em geral, pode-se afirmar que o debate sobre as raízes da situação educacional brasileira aponta um Estado sem projeto educacional. As políticas são imediatistas, elaboradas sob a pressão do ensejo. $\mathrm{O}$ investimento educacional é retorno a longo prazo, o que não interessa aos governantes, muito mais voltados para o sucesso imediato da carreira política.

O discurso estatal propõe corrigir as falhas da atuação do governo anterior. A sua gestão, ao contrário, “terá por resultado um produto bem feito, caracterizado pela melhoria das desigualdades sociais de acesso à 
escola, pela melhoria das condições dos prédios, dos professores e do ensino" (ZANOTTA, 1987, p. 229).

No discurso, cada gestão coloca os problemas educacionais no passado, acenando para uma rede escolar idealmente concebida professores qualificados, estimulados e bem remunerados, as condições de ensino iguais às formas de atuação do Estado, mais eficazes.

Tal situação gera a manipulação dos sistemas de ensino de acordo com os interesses ou doutrinas partidárias, a descontinuidade das ações, uma vez que os tempos dos ciclos políticos são sempre bem mais curtos que o necessário para a maturação de políticas de educação nacionais e regionais. Por esta e outras razões, quando se fala em políticas públicas, especificamente em educação, logo vem à mente, medidas implantadas unicamente pelos aparelhos estatais e/ou agências governamentais e, o que é pior, em corrupção, desmando, clientelismo, descompromisso, inoperância e outros.

Políticas públicas não se confundem com políticas governamentais. Mesmo quando se realizam em uma conjuntura, com finalidades emergenciais e de curto prazo, viam mudanças a médio e a longo prazo. Por isso não são sinônimos de políticas estatais, uma vez que não são privativas do Estado. Elas não se confundem com posições, discursos e portarias. As políticas públicas envolvem pactos com entre os atores sociais. A efetivação supõe avanços institucionais adequados à negociação, com o suporte técnico operacional, além dos recursos financeiros necessários, com acompanhamento e controle da sociedade.

O espaço público transcende o aparelho de Estado, incorporando a sociedade civil, publicizando os espaços privados e politizando as relações sociais nas múltiplas dimensões.

O pacto democrático é extremamente importante para impedir pensar as políticas públicas apenas como dever do Estado, direito do cidadão. Uma sociedade é forte e viva, se os seus componentes têm plena participação no desenvolvimento dela.

No Paraná, a despeito do discurso de participação, autonomia, descentralização e gestão democrática, fortemente enfatizadas no Governo Requião, não se firmou nenhum pacto entre os atores interessados no desenvolvimento da educação. Por quê? Sabe-se que o pacto supõe a integração das políticas educacionais às políticas públicas, o que só é possível se os professores, alunos, pais e comunidade, forem reconhecidos como sujeitos e agentes do processo.

Nesse sentido, as muitas indagações e inferências feitas foram delineando a presente investigação, conduzindo ao aprofundamento da análise da proposta Construindo a Escola Cidadã no Paraná, no sentido de não apenas discutir as fragilidades e omissões do sistema e da escola, 
mas sim de compreender: o poder público, naquele período histórico, formulou um projeto educacional e conseguiu implementá-lo? Como se deram a articulação e a continuidade do projeto? Como a escola e os atores sociais reagiram às propostas da Secretaria de Estado da Educação?

A hipótese que permeou o trabalho é a de que o baixo investimento público em educação é característico para o setor educacional. O governo proclama-se intérprete das aspirações maiores da nacionalidade e a sociedade civil, sem poder de pressão colabora para que a definição/implantação das políticas educacionais fiquem restritas ao aparelho do Estado. A intenção e a ação não se completam na prática concreta, causando descontinuidades e a sucessão infinita de tentativas para buscar as causas do descompasso.

Esta hipótese foi construída a partir das seguintes constatações:

- uma proposta não de governo não é um raio em céu azul, mas uma articulação de questões situadas e com diferentes atores políticos; um governo não é o único autor do seu projeto. A implementação da proposta depende da capacidade que demonstre de agregar atores sociais: ao adquirir corpo, o projeto público já não se rege por sua formulação original, mas redimensiona-se, incorporando significações políticas dos atores que agrega;

- construir a historiografia de uma política pública é indagar que fatores promoveram a sua viabilidade, buscando perceber as mudanças de significação ao longo de sua realização, como os atores apropriaramse das propostas.

A proposta denominada Construindo a Escola Cidadã no Paraná para uma "nova era na educação" passou a direcionar a política educacional do Estado, no período 19911994, configurada no Governo Requião e consubstanciada no Plano Setorial de Educação que dava prioridade à educação, à participação da comunidade, à descentralização das ações pedagó-gicas, à municipalização e à autono-mia administrativa das escolas, o que gerou intensa expectativa no magis-tério.

A proposta visava à construção de uma Escola Cidadã em que todos pudessem exprimir-se livremente. A autonomia foi considerada o único meio pelo qual as escolas e os professores poderiam apropriar-se da situação e decidir os meios para transformá-la. O projeto político-pedagógico deveria traduzir as expectativas e propor as ações da comunidade escolar para a construção de uma nova escola pública. Para melhor compreender a visão dos atores envolvidos na proposta, vale explicitar que o documento Construindo a Escola Cidadã, na forma de exposição, apresenta, de uma lado, os princípios básicos (linhas diretrizes que apontam as áreas preconizadas); de outro lado, indica as questões básicas da política 
educacional, ou seja, as linhas operacionais que constituem as maneiras pelas quais se propõe viabilizar o atendimento às áreas destacadas. São princípios orientadores da Escola Cidadã: consolidação democrática, estabelecimento de comunicação direta da Secretaria com as escolas e delas com a comunidade; incentivo às escolas para que elaborem e executem autonomamente seus projetos pedagógicos; criação de um sistema de avaliação do desempenho escolar, essencial para a implantação do Currículo Básico, público e democrático, que inclua tanto a comunidade interna, quanto a comunidade externa e o poder público. As questões básicas da política educacional são: elaboração do projeto político-pedagógico pelas escolas; implementação do Currículo Básico para a escola pública paranaense; autonomia e gestão democrática das escolas; consolidação do Ciclo Básico de Alfabetização; municipalização do ensino fundamental de $1^{\text {a }}$ a $4^{\text {a }}$ série; proposta do Regimento Escolar para os estabelecimentos da rede pública do ensino (apresentada pela Resolução 2000, de 11 de junho de 1991), sob a forma de Regimento Escolar Único; constituição dos Conselhos Escolares; proposta de reestruturação do ensino de $1^{\circ}$ e $2^{\circ}$ graus regular, supletivo e educação especial; programa de capacitação de docentes e de integração dos três graus de ensino Programa de Integração; extensão do Ciclo Básico para 4 anos (proposta de eliminação da reprovação de $1^{\mathrm{a}} \mathrm{a}$ $4^{\mathrm{a}}$ série, apresentada pelo Decreto $\mathrm{n}^{\circ}$ 2325, de 25 de maio de 1993); substituição de eleições diretas para diretores por consulta à comunidade escolar; expansão, recuperação e manutenção da rede física.

Considerando-se o objetivo do trabalho, optou-se por focalizar as diretrizes: consolidação da gestão democrática e incentivo às escolas para que elaborem e executem autonomamente seus projetos políticopedagógicos. Com base em tais diretrizes, as linhas operacionais: programa de capacitação docente; elaboração do projeto políticopedagógico; eleição de diretores, implantação do Conselho Escolar e elaboração do Regimento Escolar. Têm-se como eixo definidor as questões da cidadania, autonomia, participação, descentralização e gestão democrática (por se constituírem as características mais marcantes do período). O porquê de a escolha, dentre as questões básicas da proposta, recair sobre as listadas anteriormente, foi por entender-se ser mais congruente analisar as ações inovadoras, ou seja, aquelas que visam dar um aspecto novo; adaptar a novas condições algo que esteja superado, mudar para melhor, enfim, aquelas ações que objetivam introduzir novas medidas relativas à política educacional. Partindo do pressuposto de que, quase nunca as r formas alteram de fato os princíp e as bases do sistema escolar, são e a 
que, em alguns casos, têm introduzido inovações de alcance social. As temáticas identificadas e vistas à luz da teoria, foram trabalhadas juntamente com as falas dos atores sociais envolvidos, ou seja, a representação de cada um deles sobre os temas. Para tanto, os interlocutores que participaram da pesquisa foram: presidente da União Nacional dos Dirigentes Municipais - Undime; Superintendente da Secretaria de Estado da Educação - SEED; Presidente do Conselho Estadual de Educação - CEE; Chefe da Equipe de Ensino do Núcleo Regional de Educação de Ponta Grossa - NRE; Chefe da Equipe de Ensino do Departamento de Ensino de Primeiro Grau da Secretaria de Estado da Educação - DEPG/SEED; Presidente do Sindicato dos Professores das Escolas Públicas Estaduais e Municipais do Paraná APP Sindicato; Chefe da Coordenadoria de Integração e Capacitação de Profissionais de Ensino da rede Pública - CICAPE

Feitas as considerações pertinentes, apresenta-se inicialmente a intenção da proposta e , em seguida, a implantação da Escola Cidadã no Paraná.

\section{A intenção}

Tomando emprestada a expressão Escola Cidadã e inspirado nos seus pressupostos, Moacir Gadotti elaborou a proposta Construindo a Escola
Cidadã no Paraná, a qual veio a constituir-se no Projeto Educacional do Estado do Paraná no Governo Requião (1991-1994).

Para GADOTTI (1992), esta escola é certamente um projeto de construção histórica, horizonte, crença. Atribui-se-lhe o papel de formação para a cidadania, para o que ela própria deve incorporar as características da cidadania, como instituição autônoma, plena de participação, ou seja, constituir-se em espaço de exercício da liberdade e autonomia, da construção de relações, não de dominação, mas do reconhecimento do outro, o que implica numa ordem de direitos e deveres.

A Escola Cidadã surgiu no Paraná como resposta à burocratização do ensino e à sua ineficiência. Surgiu como resposta à falência do ensino oficial que, embora seja democrático, não consegue garantir a qualidade do ensino. Ainda, surgiu da idéia do novo porque a Escola Cidadã é o nome que se deu a partir do mote, é a Constituição Cidadã feita pela sociedade e a escola cidadã deveria ser uma escola que respondesse às exigências mínimas de uma cidadania decente (...) Nós queríamos uma escola cidadã e para isso precisava ter autonomia, condições de decidir, possibilidade de elaborar o Projeto Político Pedagógico. (MÂNFIO, 1995)

A concepção pedagógica orientadora da ação da escola é um 
mote para exprimir o entendimento de que, na escola, sem a interferência do Estado/SEED, pela criatividade dos docentes, surgirão iniciativas e experimentos que gerarão a inovação educacional e a autonomia escolar. A inovação a autonomia são constituintes essenciais do projeto pedagógico visando desenvolver práticas que respeitem a pluralidade filosófica e cultural das comunidades.

O quadro teórico da Escola Cidadã sugere que a Secretaria da Educação não pode ter proposta pedagógica. Ela tem que ter uma proposta política de assegurar espaço para a pluralidade, uma vez que parece haver sempre uma tentativa por parte do Estado de impor uma hegemonia ideológica, política e filosófica. Parte da hipótese de que o desempenho escolar depende primordialmente do projeto pedagógico, elencando os princípios norteadores da política educacional: consolidação da gestão democrática, participação comunitária, elaboração do projeto políticopedagógico, capacitação de professores e criação de sistemas de avaliação permanente.

\section{A obra: a implantação da proposta Construindo a Escola Cidadã no Paraná}

O Plano de Governo Requião caracterizou-se pela preocupação com a mudança do sistema educacional e com a transformação do Estado, que deixava de ser predominantemente agrícola, a fim de atender às crescentes demandas urbanas por saúde, educação e segurança. Para esse fim, procura, na orientação dos programas, engajar progressivamente a sociedade civil organizada na discussão, execução e avaliação de suas ações.

Para a operacionalização da proposta, procedeu-se à redefinição das funções da Secretaria de Estado da Educação e à criação de mecanismos de gestão autônoma. A Secretaria de Estado da Educação deixa de exercer papel centralizador, ampliando a autonomia administrativa e financeira das escolas. Conforme do documento Orientações para elaborar o projeto político-pedagógico das escolas, a escola deve elaborar seu projeto, através da elaboração crítica da comunidade escolar, identificando o retrato que faz de si mesma no presente e o que deseja ser no futuro.

No Centro de Treinamento do Magistério do Paraná - CETEPAR, iniciou-se a implantação da proposta pedagógica, através da entrega de cinqüenta e três dossiês de escolas, indicadas pelos chefes dos Núcleos Regionais de Educação como escolasmodelo dentro do contexto da região. Com os dados e análise dos dossiês elaborou-se o documento Construindo a Escola Cidadã, que configura o desafio assumido pela Secretaria de inovar o Sistema Educacional do Paraná.

O Regimento Escolar Único, implementado pela Resolução 2000 
de 11 de junho de 1991, complementa os avanços educacionais, assim como a implantação dos Conselhos Escolares, essenciais à gestão democrática e colegiada das instituições de ensino. Foi criado o Fundo Rotativo, objetivando a descentralização financeira para que as escolas pudessem atender a suas necessidades cotidianas, material de consumo e pequenos reparos.

Para a capacitação dos profissionais da educação, implementou-se uma sistemática de cursos de 80 horas, realizados pelos professores nos locais de trabalho, oportunizando condições de educação permanente aos 70.000 professores da rede pública do Paraná (estadual e municipal). Buscou-se concentrar esforços na universalização do ensino fundamental, a ampliação de oferta do ensino de $2^{\circ}$ grau, a elevação do desempenho qualitativo.

\section{O que apontam os dados em termos de uma análise: a $\operatorname{Re}(f o r m a)$ Escola Cidadã}

A análise da fala dos atores entrevistados ajudou a verificar o que se colocou como hipótese de trabalho, ou seja, o baixo investimento em educação, característico da política para o setor, também, a intenção e a ação não se completam na prática concreta. Constatou-se que alguns atores crêem a proposta educacional ser voltada para atender às aspirações dos cidadãos; eles não perceberam o jogo do poder e os interesses que lhes orientam a organização administrativa. Usualmente interpretam os desvios da aplicação das normas preestabelecidas como conseqüência de posturas individuais de setores do grupo dirigente no poder.

Encontram-se, porém, críticas e questionamentos quanto à eficácia da proposta. Embora a idéia de racionalidade da administração educacional, em que o Estado aparece como neutro e imparcial, tenha obscurecido a percepção do processo que aí se desenvolve. Observaram-se colocações que aparecem na fala dos entrevistados e que apontam as contradições da proposta analisada. É um processo que possibilita contradições de dois lados: 1 . O exercício e consolidação do projeto por parte do Estado; 2. A negação por parte dos atores envolvidos, é tendência que pode ser resultante do desgaste do próprio sistema educativo e dos resultados.

Alguns atores do sistema educacional, por terem uma visão de cunho mais conservador e/ou imbuídos de uma visão tecnicista, não conseguem fazer repercutir, nem incorporar, sentir os anseios da maioria da população e, assim, lhes abrir possibilidade real de participação. Outros, em vista da posição que exercem na estrutura do poder, olham a realidade em função da percepção que o exercício do cargo lhes possibilita (a exemplo de funções como a do presidente de alguns 
sindicatos e associações).

As críticas dos entrevistados são mais claramente identificadas em relação à manipulação política e à arbitrariedade na tomada de decisões, à descontinuidade dentro da própria política educacional no período 9194. Concorda-se com o representante da APP - Sindicato e a Chefe do Núcleo Regional de Educação quando se referem à liberdade dos novos governos estabelecerem propostas inovadoras em nome da democracia. O que não se pode aceitar, na gestão educacional brasileira, é a descontinuidade, a falta de propostas mais consistentes que transformaram os governos num repositório de planos concebidos aleatoriamente, sem vínculos maiores com as necessidades mais prementes do sistema educacional como um todo. A descontinuidade tem como conseqüência o abandono e/ou assunção precipitada de medidas que sequer foram implementadas, afora a ausência sistemática de capacidade maior para distinguir o essencial do acessório, tornando a administração educacional um corpo extremamente casuístico e contraditório.

Em relação às linhas operacionais analisadas no projeto Escola Cidadã, percebe-se que os entrevistados fazem críticas quanto à aplicação de suas propostas - Programa de Capacitação Docente e a Valorização do Magistério, construção do Projeto Político - Pedagógico pelas escolas e a Consolidação da Gestão Democrática das Escolas, enquanto forças capazes de eliminar a prática da interferência política nas escolas.

\section{Programa de Capacitação Docente e Valorização do Magistério}

É na terceira gestão do PMDB que se desenvolvem diversas ações de aperfeiçoamento e atualização de docentes, tais como: cursos presenciais e à distância, eventos de extensão, assessorias, grupos de estudos, etc., sob a responsabilidade diretas das Instituições de Ensino Superior. Conforme dados coletados, já no plano do primeiro governo - José Richa - foi incluída a questão da integração dos três graus de ensino e discutido, inclusive, que a capacitação docente deveria ser feita pelas Universidades. No entanto, só vai tomar caráter institucional no Governo Requião. Nos dois primeiros governos do PMDB, muitos professores participaram da elaboração dos planos de governo, ministraram cursos, palestras, o que não teve um cunho institucional; portanto, não havia um acordo formal entre as Secretarias de Educação e as Universidades.

A idéia de integração foi apresentada em junho/91, num Seminário realizado em Ponta Grossa - PR, e firmado o convênio em novembro/92, quando é assinado o Documento Plano de Capacitação/Integração do 
Magistério Paranaense.

Ao estabelecer uma política de integração do $3^{\circ}$ grau com os demais graus de ensino, Requião retoma um dos principais problemas da educação nacional, vastamente discutido nas décadas anteriores, havendo consenso quanto à participação das Universidades na capacitação docente (cf. Marli ANDRÉ (1994), Luiz Carlos de FREITAS (1992) e outros).

O processo de instituição de uma política de integração dos três graus de ensino, retoma a discussão da educação dos professores no que se refere às deficiências da formação, à qualidade das licenciaturas e à inadequada formação dos docentes em serviço. Ressalta, ainda, o descompromisso das Universidades frente ao ensino fundamental e à excessiva concentração dos programas de capacitação nas Secretarias de Educação Estaduais e Municipais, com uma programação de cursos esporádicos e distantes da realidade dos docentes, o que vinha sendo bastante criticado.

Embora contando com aspectos tão relevantes, uma vez que o programa caminhou numa concepção acertada, envolvendo diretamente a Universidade, enquanto agência formadora e o Governo Estadual como agência contratante, o mesmo não se pode dizer do processo de implantação: certas ações e descasos do Estado concorreram para inviabilizar a maioria dos objetivos estabelecidos na proposta.
A fala do Superintendente da Educação apresenta expressões importantes ao destacar a necessidade do professor capacitar-se, carregada de falseamentos do ideário neoliberal e coerente com as exigências feitas pelo Banco Mundial ao Brasil. A proposta inicial de capacitar 70.000 professores, que cada professor deveria cumprir 80 horas em cursos presenciais e à distância teve um período de apogeu e logo foi desestruturada. A capacitação dos docentes, a qual poderia habilitá-los para a concretização das outras linhas operacionais da Escola Cidadã, primeiro foi interrompida por falta de verbas e, posteriormente, pela questão da certificação e pela falta de vontade política na solução dos desencontros entre as instâncias envolvidas.

Em função da análise, acredita-se que nunca houve, de fato, intenção de integrar os três graus de ensino. Houve muito mais um conceito de terceirização do trabalho, uma vez que o CETEPAR e os Núcleos Regionais não estavam dando conta da execução da proposta.

Da mesma forma, a valorização dos docentes ficou só no papel, e os salários gradativamente achatados. $\mathrm{O}$ processo de deterioração iniciado nos anos 70 continua, a categoria é desmobilizada (culminando, segundo dados fornecidos pelo Presidente da APP - Sindicato, em três a cinco exonerações por dia, no ano de 94).

Apesar dos professores serem considerados desqualificados pela 
SEED, e caber à Universidade, a obrigação de re - formar o pessoal que foi formado, a continuidade ser afetada, pode-se creditar alguns ganhos na execução do programa de capacitação docente, que merecem ser destacados em função dos avanços qualitativos produzidos:

- a integração entre ensino superior e o ensino fundamental é possível e desejada:

- a sociedade política e a sociedade civil devem estar articuladas. O apoio da sociedade política não deve ser desprezado, podendo contribuir ou não para que os programas se viabilizem;

- os acordos e parcerias são necessários, tendo em vista que os recursos em educação são escassos e o governo, por si só, não tem condições de elevar o nível de qualidade para o ensino público;

- a escola, embora atue conforme o instituído, também é capaz de abrigar contradições e conflitos pela introdução de novas idéias, abrindo perspectivas para a mudança;

- o espaço de contradição existente na escola, devidamente explorado pelos envolvidos, abre perspectivas de mudança, deixando de considerá-la como mera vontade estatal e que elementos da sociedade civil podem e devem contribuir para a melhoria do ensino;

- os gestores da educação paranaense parecem não ter percebido que o programa de capacitação seria fundamental para viabilizar as demais políticas educacionais. Se ele tivesse alcançado êxito, certamente, outras políticas do Governo Requião e de outras gestões anteriores, poderiam ter sido implantadas e/ou consolidadas com sucesso, favorecendo a compreensão e a aceitação de políticas como as do Ciclo Básico de Alfabetização, o Currículo Básico, a construção do Projeto Político - Pedagógico, a implantação e dinamização do Conselho Escolar, além de assegurar a continuidade e o aprofundamento da linha teórica adotada pela SEED.

Por todos estes aspectos, é possível perceber que o programa de capacitação docente que contemple diretrizes básicas, de uma concepção teórica claramente explicitada, do que é e de como deve ocorrer a educação continuada, que assegure a ela cientificidade e continuidade.

\section{Elaboração do Projeto Político- Pedagógico da Escola}

No Governo Requião (19911994), a elaboração do Projeto político-pedagógico objetivava incentivar a autonomia da escola e a criatividade dos docentes. Para desencadear o processo de elaboração, inicialmente, a Superintendência da Educação da SEED solicita a indicação aos Núcleos Regionais a indicação de duas escolas por município que apresentassem ação inovadora e bom desempenho, 
objetivando conhecer o cotidiano delas. Foram encaminhados pelos Núcleos, cinqüenta e três dossiês contendo mil e trezentos relatos inovadores, dos quais foram selecionados quinhentos, para divulgação no Seminário Brasileiro de Inovações Educacionais, realizado em Curitiba - PR.

Esta medida que, aparentemente, objetivava apenas conhecer o cotidiano das escolas e não criar mecanismos de apoio às iniciativas da escola que se rotulava "inovadora", revelou-se ser mais uma ação improvisada e com o objetivo de marcar pela diferença, pelo novo. Conforme relatam os atores envolvidos, os projetos apresentados nada tinham de inovadores, e não foram divulgados posteriormente para as escolas públicas do Paraná. O quadro teórico sobre Inovações, constante dos Anais do Seminário de Inovações Educacionais parece não ter sido considerado pela SEED, uma vez que o processo de inovação pressupõe intencionalidade, conhecimento da situação, dos recursos disponíveis, dificuldades, limitações e, principalmente, tempo. Segundo Gadotti, o tempo de inovação requer "tempo político (momento oportuno); tempo institucional (questão escolar); tempo escolar (calendário - não adianta inovar no final da gestão) e existe um tempo a fim de madurecer as idéias".

Assim, em meio a ações apressadas e de pouca repercussão, com as informações insuficientes no documento Construindo a Escola Cidadã, as escolas viram-se obrigadas a elaborar o projeto político-pedagógico, e sem qualquer vinculação com uma proposta pedagógica elaborada pela SEED. Não se considerou o Currículo Básico elaborado na gestão anterior (87-90), nem a Pedagogia Histórico-Crítica que o orientou. Embora contendo um potencial renovador das atividades educativas da escola - o projeto político-pedagógico foi visto mais como uma tarefa burocrática, sem repercussão no trabalho escolar. Não houve discussão suficiente sobre o assunto na maioria das escolas, nem a participação dos pais e da comunidade como seria desejável.

A partir de tais colocações, podese sentir a perplexidade dos professores quando conclamados a elaborarem o projeto da escola. As mudanças em educação, em qualquer nível, constituem uma série de processos e uma pluralidade de relações de alto nível de complexidade, que é sempre difícil de desenvolver com acerto, principalmente, pelo fato de que a inovação educativa deve ser pensada não como uma simples realização de experiências ou projetos pedagógicos ocasionais, fragmentários, mas como um processo com um perfil e características que devem ser respei-tadas, caso se pretende inovação séria e comprometida.

Pelo cuidado que requer, a SEED revelou, mais uma vez, postura fortuita, outras, próprias de atitudes 
de centralização e autoritarismo dos dirigentes governamentais. Postura percebida, quando foram convocadas as equipes dos Núcleos Regionais para receber as orientações a respeito da proposta - a qual já veio pronta e os Núcleos só receberam as orientações quanto ao repasse para as escolas.

Após o primeiro impacto, que ocasionou atitudes as mais diversas por parte dos docentes e dirigentes das escolas, a SEED preocupada com a avalanche de questionamentos e dificuldades expressadas pelas escolas, enviou a elas textos relacionados à temática, com o objetivo de orientar e facilitar a elaboração do projeto nas escolas públicas. Entretanto, não foram suficientes para dirimir as dificuldades encontradas pelos professores na execução da tarefa. Este fato remete à discussão sobre o envolvimento dos profissionais em ambiente de trabalho, envolvimento que parece tanto mais abrangente quanto maior for a clareza dos propósitos a seguir, contribuindo para que as decisões coletivas possam contornar medidas impostas pelos órgãos da administração do ensino e/ ou para a construção de um projeto coletivo na escola. É válido ressaltar que, num grupo heterogêneo e numeroso, o nível de participação é desigual.

A indicação da SEED no Projeto Construindo a Escola Cidadã de que a autonomia da escola deve se assentar na diversidade cultural e a ausência de uma proposta pedagógica em nível de sistema contribuiu sobremaneira para o aparecimento de inúmeras dificuldades na elaboração do projeto político-pedagógico das escolas. O pressuposto defendido por Gadotti - que não se constrói um projeto sem uma direção política, um norte, um rumo - implica o abandono do Currículo Básico pelas escolas que, sem uma direção, impõe limitações à instauração de um projeto.

Além destas limitações explicitadas, existiram outras que obstaculizaram a elaboração do projeto pelas escolas, uma vez que, em nível de discurso, a SEED estabelece a elaboração de um projeto que se apoia no desenvolvimento de uma consciência crítica, no envolvimento das pessoas - comunidade interna e externa à escola, na participação e na cooperação de várias esferas do governo, na autonomia, responsabilidade e criatividade como processo e como produto do projeto e, no entanto, na prática desenvolvida, há um distanciamento, desarticulando teoria/prática.

Apesar do quadro desanimador no que tange à implementação do projeto político-pedagógico, são percebidas algumas conquistas: algumas escolas conseguiram a contratação de professores para atuarem em projetos especiais como recuperação paralela, instrutores para fanfarras, para oficinas pedagógicas, e outros. Por certo, será preciso avançar mais no sentido de obter maior autonomia no 
processo como um todo.

\section{Consolidação da Gestão Demo- crática da Escola}

Historicamente, a gestão democrática da escola pública paranaense é uma prática ainda em implantação. As decisões, no âmbito escolar, estiveram centradas nos dirigentes escolares. Em 91, a SEED estabeleceu na proposta Escola Cidadã a consolidação da gestão democrática definindo como linhas operacionais, o Regimento Escolar Único - REU para estabelecimentos da Rede Pública Estadual de Ensino, a eleição direta para diretores e a criação dos Conselhos Escolares.

Em relação ao REU, a SEED, indiferente aos postulados referentes à elaboração do Regimento, e contrariando os defendidos na proposta Escola Cidadã, caminha em direção oposta, uma vez que impõe para todas as escolas o Regimento Escolar Único, que não foi sequer discutido pela comunidade escolar. Medida esta, que desagrada o próprio Conselho Estadual de Educação, que ao contrário proposta da SEED, estabelece normas para que cada escola elabore seu próprio regimento, ocasionando intensas discussões.

O que se constata é que os obstáculos colocados na operacionalização do REU, não decorreram do desconhecimento dos pressupostos teóricos e procedimentos didáticos, mas da dificuldade da SEED para relacioná-los com as práticas educativas efetivadas. A SEED, através dos gestores, não considerou a questão da democratização do poder na escola, continuou agindo autoritariamente, $o$ que dificultou a intensificação do diálogo na escola.

Da mesma forma, a criação dos Conselhos Escolares que poderia contribuir para uma gestão democrática da escola, foi tumultuada. Sem dúvida, é uma das medidas adotada pelo Governo Requião que merece ser destacada por seu cunho democratizante e de participação. Entretanto, a SEED condiciona a avaliação e o desempenho dos professores e especialistas, para fins de ascensão na carreira, à criação do Conselho Escolar. Premidas pelo tempo, as escolas formaram o Conselho Escolar sem consulta à comunidade escolar, não aproveitando um espaço aberto para o exercício da democracia.

Mesmo tendo avançado em relação a outros Estados (São Paulo, por exemplo), quando estabelece competências deliberativas, normativas e consultivas, e que na legislação específica aos Conselhos revelar uma concepção em que eles são percebidos como instrumentos de democratização da gestão escolar, o mesmo não se pode dizer em relação à forma como foram instalados nas escolas públicas do Paraná. Nas escolas os componentes do Conselho foram escolhidos mediante indicação dos diretores e não por processo eleitoral, 
o que seria, por certo, um procedimento mais democrático.

De fato, o atropelo na divulgação dos preceitos legais, na composição dos Conselhos, na posse dos membros e a ausência de mecanismos de acompanhamento e avaliação, revelam a face autoritária do Estado. As tentativas de envolvimento e de participação de segmentos da sociedade civil nos rumos da política educacional paranaense são prejudicadas pela centralização das ações do grupo no poder.

Considerando-se, também, o Conselho Escolar como um elemento característico das relações do sistema educacional, aponta-se o pequeno espaço de concretização percebido. $\mathrm{O}$ início da prática foi fortemente marcado por insucessos, não eliminando a possibilidade dos erros gerados na dinâmica, apontarem alternativas viáveis para o futuro. $\mathrm{O}$ Conselho Escolar pode ser um aprendizado em termos de organização da escola, uma iniciação da comunidade em práticas de cidadania e, sobretudo, um elemento gerador de transformações no relacionamento de poder que se estabelece dentro da escola e do sistema de ensino. A viabilidade acontece na medida em que se dêem atribuições reais aos membros do Conselho, o que não acontece, quando só se atribuem responsabilidades menores, quando os integrantes são cooptados por meio das lideranças tradicionais da escola, quando a duração do mandato é muito limitada e as reuniões esporádicas (impedindo um processo coletivo de aprendizado e criação).

Vale dizer que os membros dos Conselhos poderão participar da definição e da execução da política educacional. A participação, por sua vez, pressupõe maior divulgação dos direitos da população aos serviços educacionais e dos deveres do Estado na oferta de serviços; que se ampliem e que fortaleçam, dentro da administração do ensino, os espaços destinados à discussão, tomada de decisão e acompanhamento da política educacional. Pressupõe-se, ainda, que a população possa ter um mínimo de organização social.

A postura centralista é percebida, também, quando a SEED insiste na criação dos Conselhos Escolares e desmobiliza as Associações de Pais e Mestres - ApMs, constituídas nos governos anteriores, como entidades auxiliares da escola, cujo objetivo precípuo é a integração entre a comunidades e os agentes escolares no desenvolvimento de atividades assistenciais e educativas. Causa estranheza, uma vez que nesta gestão foi criado o Fundo Rotativo, e compete ao Conselho Escolar apenas apreciar e aprovar o Plano de Aplicação e prestação de contas de recursos financeiros, deixando a equipe diretiva da escola, no momento de transição, insegura quanto às competências cabíveis a cada órgão da estrutura organizacional da escola.

Não se pode negar que a medida 
constitui um avanço. Contém uma faceta democratizante que corresponde a antigas bandeiras de lutas dos educadores progressistas. Entretanto, a contradição existente entre o discurso e a ação da SEED, o baixo nível de comprometimento com as próprias políticas enfraqueceram os possíveis efeitos democratizantes que poderiam advir com a implantação dos Conselhos Escolares.

Da mesma forma, no que se refere às eleições para diretores, nos primeiros meses do Governo Requião já se percebe o autoritarismo peculiar desta gestão, quando é questionada a constitucionalidade da eleição através de consulta à Procuradoria Geral do Estado. O embate criado com a APP Sindicato, Conselho Estadual de Educação e o Fórum Paranaense em Defesa da Escola Pública Gratuita e Universal, retarda o processo e a eleição só acontece em 93, sob a forma de consulta à comunidade escolar. Indiferente à tudo, a SEED ainda obriga os diretores escolhidos a participar de um processo de capacitação, definido pela própria Secretaria, e determinando que os diretores estavam sujeitos a perderem o cargo, caso não obtivessem o resultado desejado. Estas exigências, como a destituição por conveniência da administração e a participação de $50 \%$ dos eleitores para que a consulta fosse válida, alteraram significativamente os critérios das eleições, criando um dos maiores impasses entre docentes e governo do Estado.
Em relação ao fato, algumas alegações foram feitas e não tiveram ganho de causa junto ao Supremo Tribunal Federal. É preciso reconhecer que a gestão democrática é um processo sempre inacabado e que os limites são enormes. Eles se encontram na própria estrutura do sistema educacional (vertical), e no autoritarismo que sempre o impregnou, no tipo de liderança que tradicionalmente domina a atividade política brasileira., nas próprias pessoas com pequena experiência de democracia e na mentalidade que atribui aos técnicos a capacidade de governar, e considerando o povo incapaz de exercer o governo de qualquer coisa.

É lícito reconhecer que no contexto de polêmicas e indagações quanto à escolha de diretores, têm surgido várias discussões sobre os procedimentos adotados pelas secretarias estaduais e municipais, nos últimos anos, pela pressão social pela democratização das instituições públicas que vinculam processo eleitoral ao processo democratizador. No entanto, ao se definirem parâmetros para a gestão democrática na escola, necessário se fazem alguns pressupostos que devam nortear a eleição de diretores.

\section{Considerações finais}

Feita esta análise, acredita-se que a superação das velhas práticas do sistema educacional dar-se-á, sobre- 
tudo, à medida que a sociedade civil se fortaleça, se organize. Ao se fazer tal reflexão não se quer dizer que , pelo fato de a sociedade estar ainda um pouco organizada politicamente, de ser reduzido o número de interlocutores para as propostas de mudança, o que deve constituir empecilho para que se proponha algo e que, no contexto as propostas não surtirão resultados.

Nesta altura em que se aprofunda em todos os níveis, o sentido da participação e da autonomia a todos os níveis, a construção do projeto político-pedagógico revela-se de grande acuidade. A autonomia constitui o principal pressuposto do projeto. Segundo a ótica dos entrevistados, o discurso descentralizador presente nos textos legais permite, mas não garante a autonomia da escola. Oferece, por si mesmo, uma autonomia delegada, que é quantitativamente diferente da autonomia emergente no interior da própria escola; a única, afinal, capaz de assegurar um projeto de escola autêntico. Um projeto que, como tal, tem que ser internamente construído e, a não ser assim, corre o risco de redundar em fracasso.

A ótica dos atores envolvidos, o projeto político-pedagógico constituise a espinha dorsal da autonomia da escola, o fundamento e o reflexo. Apesar de a execução dos projetos, terem dependido da decisão final do Superintendente da Educação, consi- deraram que algumas escolas avançaram, obtendo melhores condições materiais e financeiras para o desenvolvimento das propostas. Assim, acredita-se que boa parte delas não aprenderam a agir autonomamente nem a ocupar os espaços concedidos pela SEED. Para tanto, faz-se necessária a continuidade das ações, que significa a capacidade de reformular, aperfeiçoando-lhe os instrumentos de sensibilização às mudanças que ocorrem nas expectativas e necessidades dos grupos que a envolvem.

Com relação às iniciativas da administração estadual de ensino no que se refere à capacitação docente, no período analisado, os entrevistados consideraram-nas, por um lado, importantes e necessárias, por traduzirem uma preocupação com a melhoria do ensino; por outro lado, criticaram as formas como foram desenvolvidas as atividades voltadas ao aperfeiçoamento docente. Mesmo sem duvidar de que o professor prefere ser efetivamente aperfeiçoado, não há garantia alguma de que progresso pessoal e profissional seja obtido. A descontinuidade das ações efetivadas, em parceria com as universidades ou não, revelam, na ótica dos entrevistados, uma política imediatista e centralizadora.

É claro que, dentre os inúmeros problemas da educação brasileira que precisam ser resolvidos, nenhum sobreleva o da formação dos professores. E a razão é muito simples: a questão da qualidade do ensino não 
será adequadamente enfrentada, sem que se enfrente a questão da formação do educador. São afirmações que parecem ser muito simplistas, e, talvez o sejam, se não forem convenientemente qualificadas.

As lutas e as reivindicações dos professores por melhores salários têm contribuído para que sejam considerados como um sindicato. E sindicato magisterial, lembra, automaticamente, reivindicação salarial, corporativismo, intransigência, greve. Os professores e os sindicatos têm sido vistos como problemas, antes que recursos; a remuneração do professor tem surgido como o fator causal da baixa qualidade do ensino. Algumas vezes, a discussão relativa à questão salarial parece até que caminha no sentido de ser adequadamente resolvida, haveria, automaticamente, a elevação da qualidade do ensino. Ela tem contribuído, também, para que sejam obscurecidos importantes fatores nas discussões sobre a questão da qualidade (DE TOMMASI, 1995).

$\mathrm{Na}$ verdade, a questão da qualidade é uma questão institucional. As ações/metas constantes das propostas precisam ser refletidas, planejadas, implantadas/implementadas e avaliadas. A melhoria da prática somente pode ser efetivada pela crítica da própria prática no momento em que ela ocorre, e não uma crítica abstratamente descrita ou executada de forma apressada/impensada, sob determinações da equipe central, e desconsiderados tempos depois para que novas atividades sejam lançadas e exigidas.

Isto posto, a inferência, quase inevitável, é que no Governo Requião, os aspectos ora salientados, foram incorporados no discurso da SEED. Um das idéias feitas subjacentes à política de capacitação docente é a de que a formação dele deve ser continuada após os anos acadêmicos, buscando, assim, corrigir as falhas da formação regular. É da competência da universidade re - formar a formação inicial do professor. Os esforços despendidos para a melhoria da qualidade do ensino (discurso) têm se concentrado ora na capacitação dos professores, ora na elaboração do projeto político-pedagógico, ora na criação dos Conselhos Escolares. A linha de atuação adotada pelos dirigentes, qual seja, a de contemplar linhas operacionais diversas em determinados momentos, denota certa descontinuidade nas ações governa-mentais, uma vez que, após implan-tadas são abandonadas, como se as escolas, dali em diante, tomassem as iniciativas e tivessem a competência e os recursos financeiros e materiais necessários para o empreendimento. Mesmo sem duvidar de que algumas escolas estão suficientemente preparadas para o deslanchar das propostas (e algumas o fazem), ainda é muito pouco para que as ações sejam, de fato, consolidadas.

$\mathrm{Na}$ verdade, a questão da qualidade do ensino é uma questão institucional. As ações/metas cons-tantes das propostas precisam ser refletidas, 
planejadas, implantadas/implementadas e avaliadas. A melhoria da prática somente pode ser efetivada pela crítica da própria prática no momento em que ela ocorre, e não uma crítica de uma prática abstratamente descrita ou executada de forma apressada/impensada, sob determinações da equipe central, e desconsideradas tempos depois para que novas atividades sejam lançadas/exigidas.

Em suma, parece que o que precisa ser melhorado são as escolas, a política educacional como um todo. A própria idéia de autonomia da escola, com estímulos ao desenvolvi-mento de um projeto político-pedagó-gico específico, pressupõe que a enti-dade a ser melhorada é a escola e não apenas (mas também) o professor e alguns outros procedimentos ado-tados.

Os elementos apontados - participação e autonomia no processo de gestão - presentes no projeto Escola Cidadã, permitem inferir que cada escola poderá constituir-se num núcleo de pressão com vistas à democratização da escola. É importante lembrar a nova ordem de responsabilidade dos atores sociais envolvidos que, não depende só da vontade individual, mas também das condições reais, objetivas. É preciso estar atento ao fato de que algumas propostas, embora sejam feitas por intelectuais compromissados com a maioria da população, requerem cuidados para que não caiam no vazio, e que elas por si mesmas não provocarão transformações. Outro fato que deve estar pre- sente é o de que, dependendo do seu encaminhamento, e por mais democratizante que seja, uma proposta poderá transformar-se numa forma disfarçada de dominação. Isso eqüivale a dizer que, ao se propor algo, é de suma importância que se encontrem interlocutores para que assumam o novo desafio que se impõe - construir um novo tempo na gestão escolar, frente às contradições históricas presentes no processo de participação dentro da escola e da sociedade.

Por certo, as ligações que vinculam as novas formas de percepção/ interlocução do Estado e sociedade ainda são muito frágeis e incertos. Todavia, a articulação de atores diversos, revela formas de participação popular em instâncias em que o Estado é um dos parceiros e não o parceiro (cf. SILVA, 1994). Tais referências colocam em cena a tarefa primordial de se refletir sobre as possíveis novas formas de sociabilidade que incorporem os grandes contingentes de excluídos, os não-organizados nas malhas da cidadania.

Num esforço de síntese final, com base nas intenções contidas entre o projeto e a ação governamental efetivada, e na percepção construída em função dos dados coletados, acreditase que há soluções para a transformação da escola em organizações inovadoras, flexíveis, respondendo às demandas educativas do público. Resta aos atores sociais envolvidos perceberem o governo com olhos renovados, que se juntem aos milhares de 
cidadãos que já estão trabalhando para que a construção da cidadania possa encontrar seus fundamentos, e os diversos projetos, hoje utópicos, sirvam como base para sua concretização/consolidação.

\section{REFERÊNCIAS BIBLIOGRÁFICAS}

1 ANDRÉ, Marli Eliza Dalmazo Afonso de. Formação de professores em serviço: um diálogo com vários textos. Cadernos de Pesquisa, São Paulo, n. 89, p. 72-75, maio/94. Fundação Carlos Chagas.

2 BALESTRERI, Ricardo Brizolla. O que é educar para a cidadania. In: Educando para a cidadania: os direitos humanos no currículo escolar. Porto Alegre: Centro de Assessoria e Programas de Educação para a cidadania-CAPEC, 1992, p. 913.

3 CASASSUS, Juan. Tarefas da educação. Campinas: Autores Associados, 1995.

4 DE TOMMASI, Lívia; WARDE, Miriam Jorge; HADDAD, Sérgio (orgs.). O Banco Mundial e as políticas sociais. São Paulo: Cortez, 1996.

5 DOWBOR, Ladislau. Governabilidade e descentralização. In: Revista Paranaense de Desenvolvimento: Economia Estado Sociedade. Curitiba, n.83, set./ dez. 1994. p.65-84.
6 FREITAS, Luiz Carlos de. Em direção a uma política para formação de professores. Em Aberto. Brasília, ano 12, n.54, p.3-22, abr./jun./92.

7 GADOTTI, Moacir. Escola Cidadã: uma aula sobre a autonomia da escola. São Paulo: Cortez. 1992.78 p.

8 GOHN, Maria da Glória. Movimentos sociais e educação. São Paulo, Cortez, 1992.

9 MARTINS, Carlos Estevam. O circuito do poder: democracia, participação, descentralização. São Paulo: Entrelinhas, 1994.

10 PARANÁ. Secretaria de Estado da Educação. Superintendência da Educação. Paraná: Construindo a escola Cidadã. Curitiba, 1992.

11 SANDER, Benno. Gestão da educação na América Latina: construção e reconstrução do Conhecimento. São Paulo: Editora Autores Associados, 1995.

12 SILVA, Maria Aparecida da. Administração dos conflitos sociais: as reformas administrativas e educacionais como resposta às questões emergentes da prática social. Tese (Doutorado), Universidades Estadual de Campinas, 1994.

13 VEIGA, Ilma Passos A. Projeto político-pedagógico da escola: uma construção possível. Campinas: Papirus, 1995.

14 ZANOTTA, Lia Machado. Estado, escola e ideologia. São Paulo: Brasiliense, 1987. 